\title{
DO AND THINK AND PLAY AND SHOW AND TELL: ARTEFACTS ALL THE TIME
}

Marc Rettig, Fit Associates, Pittsburgh, PA, USA

This is a practitioner's response to Show and tell: Accessing and communicating implicit knowledge through artefacts, a paper by Yoko Akama and her colleagues appearing in this same issue of Artifact. Their findings suggest that people assign their own meanings to physical artefacts. In the author's experience, this insight proves useful in industry work. In this paper, that usefulness is illustrated by six stories from projects, describing how the author and his colleagues and have observed and often encouraged this behaviour using indigenous, introduced, and constructed artefacts. Additionally, two theoretical areas are briefly discussed that underpin the methods referenced in the stories. The first theoretical underpinning concerns a distinction drawn from anthropology between the etic or observer's understanding of an object, and the emic or indigenous person's understanding. The second is a brief discussion of our somewhat different perspectives concerning a language of artefacts. While Yoko Akama, Roslyn Cooper, Laurene Vaughan, Stephen Viller, Matthew Simpson, and Jeremy Yuille argue that artefacts present their own embedded language, the author suggests a practical understanding of language behaviour that accepts non-verbal, non-textual elements into the lexicon.

Keywords: case studies, ethnomethodology, interview methods, language and design, playful triggers

This paper is written in response to a theoretical perspective on the use of artefacts in interviews, from the viewpoint of a practitioner who values theory and academic insight. It illustrates that the work of academics and professionals sometimes intersects. It draws examples from a 15-year consulting practice, across many different industries and corporate cultures. In these environments, my colleagues and I almost always sought to provide product teams with good methods for customer research and team collaboration (either as an explicit project goal or a desirable side effect). Like Akama et al., we found that artefacts, or playful triggers, as they call them, are useful for eliciting customer data and facilitating collaboration. We frequently employ such tools in our work and recommend them to clients.

Therefore, my own practice suggests that the findings of Akama et al. apply in industry practice as I have experienced it - with many possible elaborations and twists. While she and her colleagues present on that situation more objectively, I can report professional success using related techniques with many different teams as they sought to align product concepts and design details with the realities of customers' daily lives. Furthermore, I have found the use of artefacts, both indigenous and introduced, to be valuable in many different interview situations.

\section{GALLERY}

In the spirit of show and tell, the following "gallery" offers a series of examples from different kinds of projects and team situations. I have omitted obvious and common industry practices involving artefacts, such as task observation and prototype evaluation. Instead, I have chosen examples that relate to some of Akama et al.'s main points:

1. Artefacts indigenous to a person's world may be bearers of implicit meaning.

2. When asking people to explain something, it often helps to introduce artefacts; people assign meaning to them and use them to communicate. 
3. Sometimes artefacts become full-fledged linguistic elements - bits of language.

The table shown in Figure 1 summarizes the examples found in this paper. Each column characterizes one of Akama et al.'s main points.

\section{EXAMPLE ONE: USING TIMELINE COLLAGES TO ELICIT PERSONAL STORIES}

\section{The situation}

In this project, our client sought to publish useful information and advice to high school and collegeaged people who are about to make a major life decision, with particular focus on the decision to enter military service. The project involved multiple research activities among many different groups of people, one being a series of interviews with soldiers who had served less than six months. We asked them to reflect on the series of events and choices that led them to join the Army, and sought as detailed and accurate a telling of this story as we could elicit.
Having only a short time with each soldier, our team faced a challenge: how to quickly build rapport and trust, then elicit a detailed and forthright telling of each story. We had to devise an interview protocol before we knew which were the right questions to ask.

\section{The tool}

To assist us with this challenge, we created a timeline construction kit. The kit consisted of a large sheet of paper and a set of stickers: generic people in pink, blue, and camouflage, word balloons, thought balloons, and a set of symbols on stickers representing concepts such as places, ideas, feelings, objects, and military vehicles. We also included blank stickers in case participants wanted to make their own symbols.

At the time, we did not think of this as an application of a playful trigger method. Looking through the lens of Akama et al.'s terminology, it is clear that we were indeed employing a set of playful artefacts.

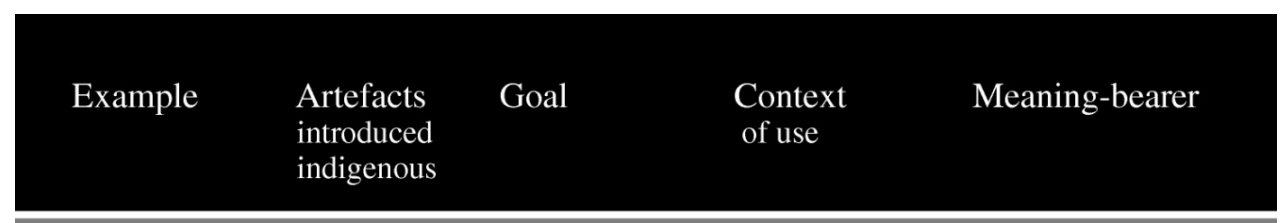

\begin{tabular}{|c|c|c|c|c|}
\hline $\begin{array}{l}\text { 1. Timeline } \\
\text { collage }\end{array}$ & Introduced & Elicitation & Interview & $\begin{array}{l}\text { Stickers, Annotation } \\
\text { Relative position }\end{array}$ \\
\hline 2. Guided tours & Indigenous & Elicitation & $\begin{array}{l}\text { Contextual } \\
\text { interview }\end{array}$ & $\begin{array}{l}\text { Existing artefacts - } \\
\text { the stuff of daily life }\end{array}$ \\
\hline 3. Doodling & Introduced & Collaboration & Anytime & $\begin{array}{l}\text { Clay, pipe cleaners } \\
\text { toys }\end{array}$ \\
\hline 4. Stickybase & Constructed & Collaboration & $\begin{array}{l}\text { Team } \\
\text { collaboration }\end{array}$ & Sticky notes \\
\hline $\begin{array}{l}\text { 5. Whole } \\
\text { document }\end{array}$ & Constructed & Collaboration & $\begin{array}{l}\text { Team } \\
\text { collaboration }\end{array}$ & $\begin{array}{l}\text { Printed document, } \\
\text { sticky notes } \\
\text { relative position }\end{array}$ \\
\hline $\begin{array}{l}\text { 6. Do-think- } \\
\text { feel cards }\end{array}$ & Introduced & Elicitation & Interview & $\begin{array}{l}\text { Pre-printed cards, } \\
\text { relative position }\end{array}$ \\
\hline
\end{tabular}

Figure 1.

Summary of examples that describe situations where artefacts helped elicit shared understanding. 


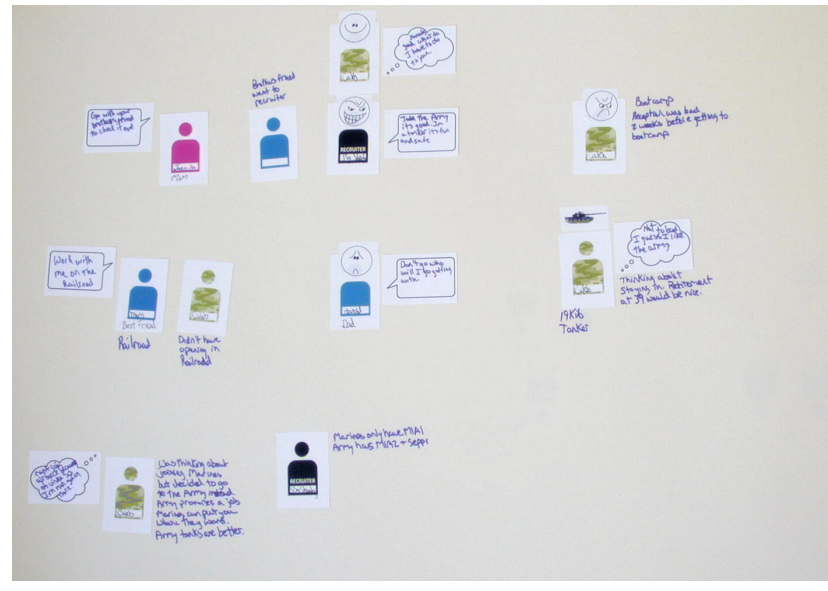

Figure 2.

A timeline collage constructed with a soldier as he told the story of his decision to join the US Army. To an outsider, this is a somewhat bland arrangement of symbols and words. To the participant and researcher, who built it together, it is a rich representation of an important life story, laden with emotion and detail. It is a sort of totem or memory palace for that story.

Some of them came pre-loaded with meaning, such as a picture of a house, while others, such as blank stickers, were open invitations to construct new meanings. And in the course of the interviews many of the artefacts were assigned very personal meanings by participants.

We asked soldiers to tell us the story of how they decided to join the military, saying, "While you talk, we will build a diagram or timeline of your story using these stickers. Maybe you can help us make a diagram that tells your real story."

Based on whatever the participant said first, we would choose an appropriate sticker and put it on the page. For example, “My Dad and my uncle were both in the military, so I guess I've always thought about it as a possibility". We would say, "Your Dad and uncle? Let's get them on the page. How about a people sticker for each? What colour should they be? And let's give them word balloons ... what kind of things did they say to you about the military?"

After the first few minutes of every interview, participants became engaged in the work of constructing a complete timeline. Most began choosing stickers and putting them on the page themselves. Many wrote words on the sheets. And they all became interested in making the picture complete. "Oh, if you have my uncle you should also put my aunt on there, because she always told me not to join". One of those resulting timeline collages is shown in Figure 2.
Lesson: Co-constructing an artefact feels different than telling a personal story

The value of this exercise was not somuch in the end result, but in what participants said as we constructed the timeline together. Even shy people told detailed stories, including revelations about their own emotions and the emotions of the people around them. I would argue that the timeline refocused some of the more personal aspects of their story. Putting a thought bubble on the timeline, and looking at it, is somehow easier than looking a researcher in the eye and revealing private emotions.

\section{Lesson: Generic symbols were assigned personal meaning, and that meaning was shared between participant and researcher}

Everyone had the same set of symbols available. But as stickers were transferred to the timeline, each was explicitly assigned a personal meaning according to its place in the story. For example, stickers of camouflaged people: "This is my uncle; I look up to him. This is my recruiter; he lied to me". For the rest of that interview, whenever the conversation turned back to the uncle or the recruiter, both participant and researcher would point back to the sticker on the page, perhaps annotating it further. Each time, the meaning assigned to that symbol became richer, and the context shared between researcher and participant became deeper. Through the course of the interview, the page became a totem or memory palace full of meaning shared only between the researcher and the participant.

\section{EXAMPLE TWO: DOING CHANGES STORYTELLING}

\section{The situation}

Our client sought to understand how well a newly designed clothes washer and dryer served the needs of their intended buyers. They placed preproduction prototypes in 12 homes chosen for demographic diversity. The goal was to get beyond interviews and surveys to see how buyers would actually use the appliances. To understand the observation, we also had to understand the role of laundry activities in the life of each particular household.

\section{The tool}

We spent several hours in each home. While our time started and ended with semi-structured interviews, the majority of it was spent watching 

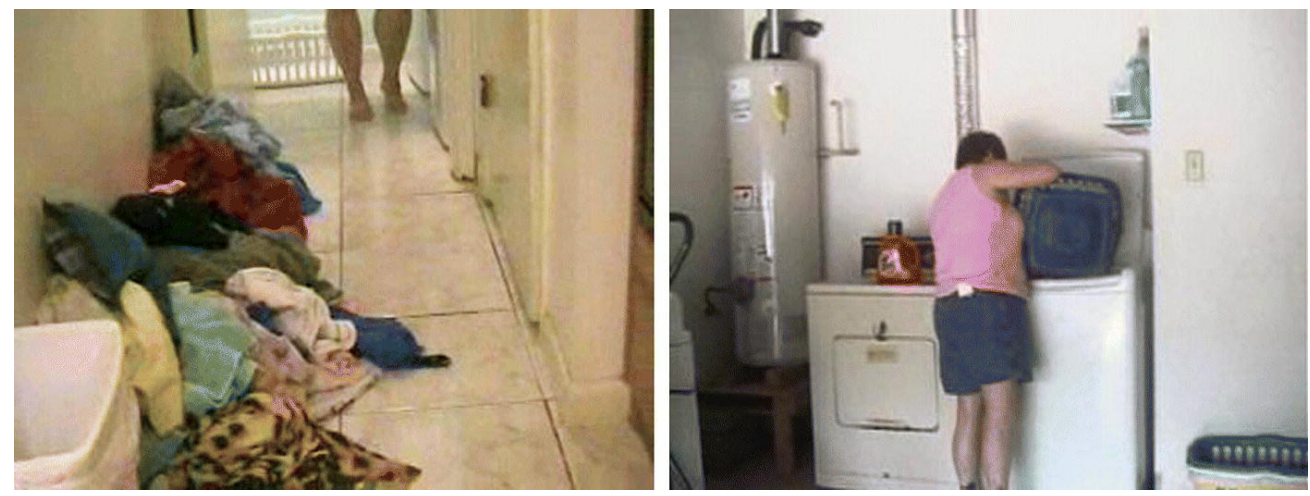

Figure 3.

Indigenous artefacts encountered during a laundry study. At left, a hallway corner deemed "the laundry basket" an artefact that becomes invisible when it is not in use. At right, a "dumper" a person who uses her laundry basket as a tool for loading the washer.

people do their laundry and asking questions along the way. So in this case, the artefacts we wanted to employ in our interview were already in the house. Using Akama et al.'s terms, they were indigenous. We did not introduce anything new into the conversation.

A story about in-context observation may seem out of place in this response to a paper about introducing artefacts during interviews. Worse, it might seem like a case of stating the obvious: “Things are important". But it seems more important to illustrate the idea that the objects that surround people's daily lives are full of assigned meaning. Sometimes simply being in the right context provides all the "artefacts" one needs to obtain the benefits described by Akama et al. The meanings are already associated with the artefacts. The job is to elicit those meanings, to create a conversation through which those meanings (many of them tacit) can be identified and articulated.

\section{Invisible artefacts}

For example, each household has a workflow associated with laundry, supported by an organizational system. In some households that system is easy to observe directly, because it is made explicit in the artefacts. Perhaps there are baskets in each person's closet labelled "whites" and "colours".

But in many households the organization is invisible. We sawone housewhere a corner in the hallway is the "laundry basket" (see Figure 3). To anyone who does not live in the house, the empty corner is like any other empty corner in any other house effectively meaningless, nameless. But to the people who live in the home that same corner has a name, and the fact that it is empty carries meaning: laundry is done!

\section{Meaning revealed through use}

Some artefacts carry tacit meaning. Which is to say, even the people who use those artefacts every day do not think to articulate their meaning. In several of the households we studied, people would casually gesture at a basket and say something like, "Those are the laundry baskets. This is for colours", and so on. But when we watched them actually do the laundry, we saw them lift the baskets full of clothes and dump the contents into the washer. So the basket was also a washer-loading tool; a device for transferring lots of clothes at once from the floor into the washer.

This was significant to the study because it was unexpected behaviour. We thought everybody would be like us, and move the clothes by hand from the basket while it sat on the floor, because neither the basket nor the top of the washer was designed with this behaviour in mind. No participants had a name for this. They just did it. The photographs in Figure 3 illustrate some of our observations.

\section{Lesson: Indigenous artefacts are a researcher's feast}

People's places and personal items are a rich and delicious potluck for artefact-based research methods. The objects in people's everyday lives are loaded with personal meaning. Often the best way to elicit that meaning is to spend time with people while they use those objects in the usual way. This is true for almost any context or activity, including the work of design teams themselves. 


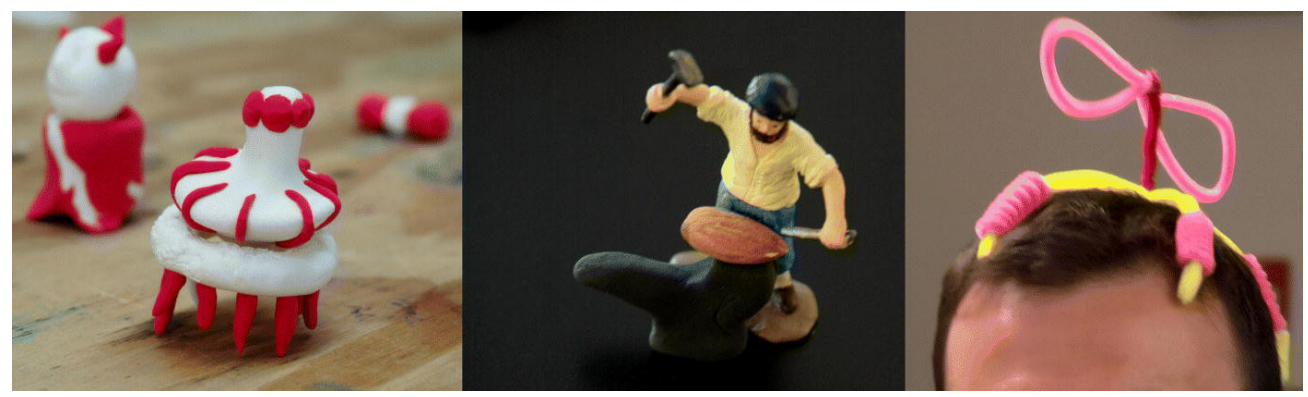

Figure 4.

Some of the things people have quietly made during work sessions, with no interruption in the group's main work activity.

\section{EXAMPLE THREE: DOODLING WITH ARTEFACTS CHANGES WORKSHOP DYNAMICS}

\section{The situation}

We often find ourselves in the position of facilitating group communication and collaborative work. Many things can hamper communication, including subtle issues of personality, politics, and group dynamics that are still a mystery to social scientists, never mind us poor consultants. When something consistently helps a group relax and work effectively, we keep using it whether or not we really understand why it works. Doodling with artefacts is one of those tools.

\section{The tool}

When a work session combines people who are unfamiliar with one another or unused to collaborating face to face, we seed the room with raw materials from the art supply store, including air-drying clay (Crayola's Model Magic ${ }^{\mathrm{TM}}$ is great), pipe cleaners, plastic animals, and markers. Unless someone asks, we often do not even tell people what these are for. We just leave them all over the tables. If someone asks why, we simply answer, "It's for you to play with if you want".

\section{The tool}

When a work session combines people who are unfamiliar with one another or unused to collaborating face to face, we seed the room with raw materials from the art supply store, including air-drying clay (Crayola's Model MagicTM is great), pipe cleaners, plastic animals, and markers. Unless someone asks, we often do not even tell people what these are for. We just leave them all over the tables. If someone asks why, we simply answer, "It's for you to play with if you want".
At some point, someone picks something up and starts twiddling with it. Sometimes, if no one is touching the toys, one of us makes something turns a pipe cleaner into a corkscrew, for example. People see it and smile. Within an hour, the tables are populated with creations and a quiet current of making things runs under the main activity of the day. It is seldom interruptive, and almost always results in little works like those in Figure 4 that surprise even the people that made them.

\section{Lesson: Playful artefacts change group dynamics}

We are not saying this is profound, we are just saying it works. No doubt there is some interesting psychology behind this observation. We have suspected since kindergarten that engaging the hands creatively while listening to the flow of conversation really does change the level of people's engagement with the group. Certainly the moments of nonverbal communication - smiles when a clay figure is placed on the table; eyes meeting when someone picks up a marker; the passing of pipe cleaners between two people these contribute to the growth of a friendly, creative group dynamic. Here is the connection our work has to that of Akama et al.: we would say that playful triggers are still playful even when there is nothing in particular to trigger. Play is just a basic human need that is too seldom mixed with work.

\section{EXAMPLE FOUR: STICKYBASE - A TEAM CONSTRUCTS A BASE OF SHARED KNOWLEDGE}

\section{The situation}

When asked about the role of technology in public schools, the team we were working with said, "We know a lot about that!" Probing further, we found what they meant was they had a large collection of 
studies, papers, and clippings about technology in public schools. But it was necessary to the project that the team have a common base of current knowledge on the subject.

\section{The tool}

We divided the collection among the team, and then asked them to read their assigned articles and make sticky notes for each important piece of information they encountered. Each note had a single main idea, fact, quote, or otherwise memorable item. The sticky notes were then placed on a long stretch of wall, and the team spent several hours organizing them into clusters or categories. In the course of this activity, many of the notes became topics of conversation. By the time the team had completed the clustering work, everyone had either read or heard about all of the resources in the original collection, and together they had constructed a common understanding of the major themes and relationships.

The next day, the team gave a "guided tour" of the wall to the rest of the department, explaining the themes and neighbourhoods of clusters (all represented by different colours of sticky notes). The wall remained up and available to the whole group for several weeks. At the end of this activity, it is safe to say that the team really did know a lot about technology in public schools. Their hard work is shown in Figure 5.

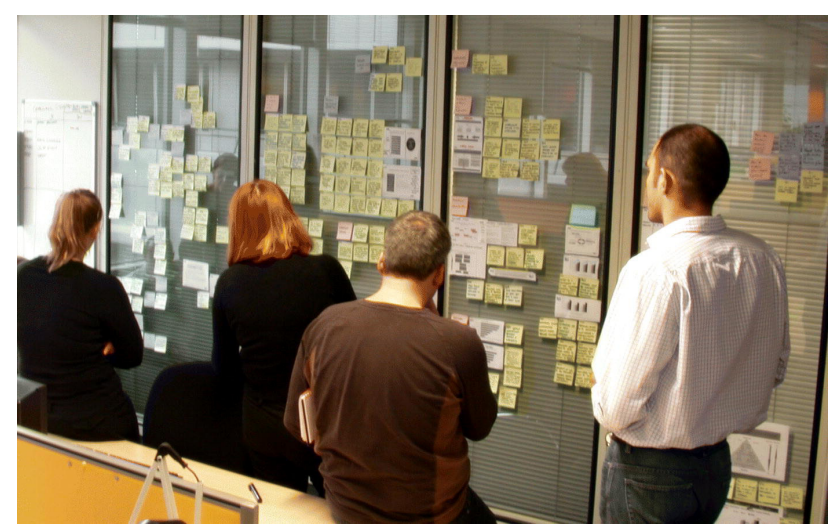

Figure 5.

A team clusters sticky notes drawn from a large collection of related documents. They are preparing to give a "guided tour" of the wall (only a portion of which is shown here) to the rest of their department.
Lesson: Making information explicit and manipulable, and doing so as a group, is a great tool for building a common base of knowledge I would add a third term to Akama et al.'s categorization of artefacts as indigenous or introduced. In this case, the artefacts were all constructed. The team members turned each idea and nugget of information in their research sources into an artefact that everyone could share, manipulate, and annotate.

It happens that paper and marker are ideal for this kind of construction, and yes, the symbols - the embedded meanings - were quite explicit. Each sticky's meaning was explained in words or a diagram for all to see. However, the group imparted new meaning to some of the sticky-note artefacts as they worked through the clustering exercise. Some stickies were so characteristic of a cluster of ideas, or so compelling to the whole group, that they came to represent an entire conversation. They took on added meaning through group use. As evidence of this, when an outsider stood in front of the wall and read the notes, he or she might be able to glean the gist of the information. But when one of the core team stood in front of the wall and used it as a memory palace for a full day of analysis and conversation, a much longer and deeper narrative would emerge. For the core team, the sticky wall was packed with meaning that was not evident in either the form or the explicit annotation on the artefacts.

\section{EXAMPLE FIVE: PHYSICALLY EDITING AN ELECTRONIC DOCUMENT}

\section{The situation}

Three team members collaborated to write a complete description of project outcomes - an 80-page document that compiles the results of weeks of work. To begin, they divided the material into sections, and each person was assigned a part to draft. This resulted in a large compilation of material in different voices, each section having an organization that had evolved under the hand of its individual author. The challenge was to integrate all this material into a coherent, compelling document with a single voice. 


\section{The tool}

All of the document pages were printed and laid out on the floor. This required eight to 10 metres of space. The team then walked the document, gaining a common understanding of its current state and organization. Until that moment, the document was only viewable one page at a time on computer screens. Now it was viewable as a whole: manipulable and sharable. Once the authors agreed on a new organization, they could physically pick up the pages and move them. As they identified issues, settled on changes, and agreed on tasks, they placed sticky notes directly on the affected pages. Again, everyone could see and alter both the whole and the details of each part.

The time and number of editorial iterations this saved, the value of the common understanding this created, and the increase in the overall quality of the end result were all invaluable. We credit these benefits to the fact that the document as a whole, each of its parts, and all annotations and decisions were physical artefacts as you can see in Figure 6.

\section{Lesson: For many purposes, atoms are better than bits} Physical artefacts have such power for supporting collaboration, clarity of communication, and bigpicture problem-solving that we find ourselves using them in every project. Having trouble? Print it out! Represent it on stickies! Draw it on the wall!

Like the previous example, this use falls under the category of constructed artefacts. And this example goes beyond Akama et al.'s main point, which
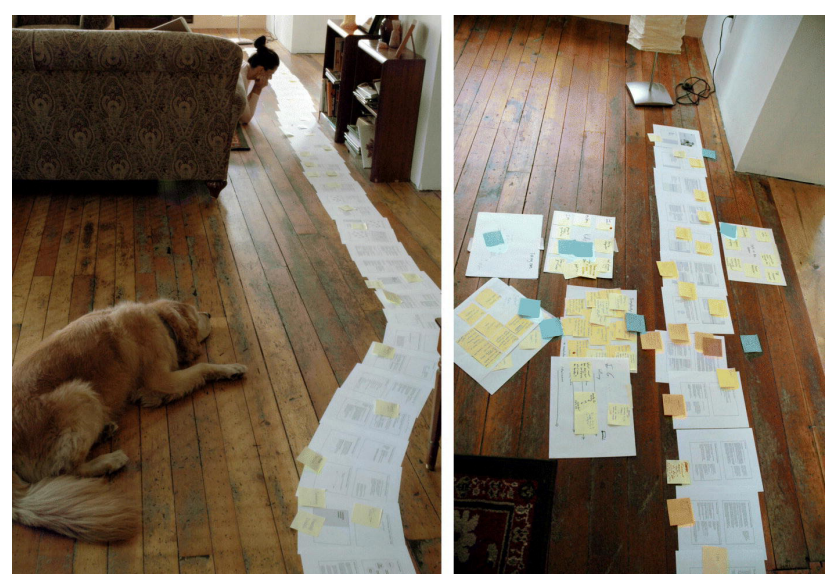

Figure 6.

Document as artefact - a draft document laid out on the floor and annotated with various colour-coded annotations. concerns the power of artefacts for interview and data elicitation situations. The point here is that the qualities of artefacts that make them so useful in those situations - their ability to carry embedded meaning, and their ability to make that meaning explicit in conversation - are the same qualities that make physical artefacts powerful as tools for problem-solving and collaboration.

\section{EXAMPLE SIX: FEELINGS MADE PHYSICAL TO HELP PEOPLE EXPRESS THEMSELVES}

\section{The situation}

A research project engaged sufferers of severe sleep apnea in conversations about personal, sensitive topics: their health, their spouse's health, sleeping together, snuggling, fears, and so on. The researchers' challenge was to gather genuine stories and accurate data in these matters despite the fact that they were strangers to the participants.

\section{The tool}

A deck of cards made it possible for participants to express the unspeakable. The team created cards in a number of "suits" or categories. Each card had a single sentence, written as though the participant had said it. Both the categories and the statements themselves were drawn from two sources: stakeholder interviews with the client managers about their goals for the research, and initial interviews with all the participants about their experience with the condition and its treatment.

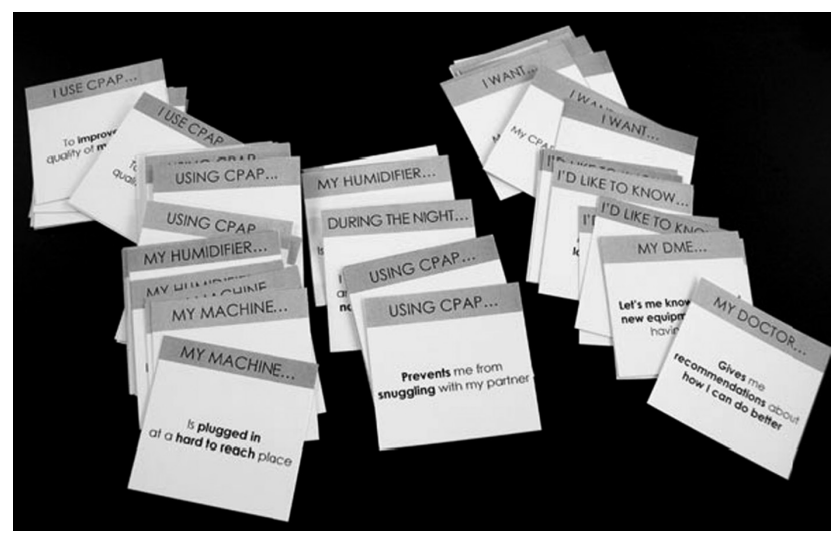

Figure 7.

A set of explicit statements on cards, used in an interview situation that dealt with personal, sensitive topics. Choosing a card is safer, less personal than speaking the sentence. 
Once again, the power of physical artefacts to carry meaning, invite assigned meaning, and make meaning directly manipulable proved invaluable. Simply choosing or not choosing a card let them say something. "This matters to me; this is irrelevant to me." Stacking and ordering cards let them express priorities. And when a participant's spouse became involved in working with the cards, differences in perception and experience became clear.

While the cards had explicit statements, we found that people often assigned their own meaning even to those very explicit words. The same card, the same words, would trigger different meanings for different people. And because of the cards we were privileged to learn those meanings. Our belief: choosing a card feels safer, less personally revealing than speaking exactly the same words that are printed on the card. The act of choosing a card is more like agreeing with someone else's statement than volunteering a personal secret. The cards can be seen in Figure 7 .

\section{A nod totheory}

The work described in the Gallery section of this paper is more grounded in knowledge gained from practice than knowledge applied from theory. That said, two areas of academic inquiry do indeed enter our thoughts, either as we plan projects or as we reflect on why they did or did not proceed as well as we hoped.

\section{Etic and emic views of indigenous artefacts}

Some linguists and anthropologists talk about the distinction between the "etic" and "emic" perspectives (Franklin, 1996; Pike, 1957, 1993). The etic perspective emerges from someone outside the culture - an observer's interpretation of customs, beliefs, or artefacts. The emic perspective is that of the insider or indigenous person. It includes embedded meanings that are not apparent to an outsider. For example, in the project concerning sleep apnea and the use of cards to elicit discussion, we saw that one couple's bed had its covers arranged so they formed a long ridge down the middle of the bed. As outsiders, we could speculate that this was a temporary condition created when they got out of bed that day. We also thought that it might be some kind of divider. Only after the card exercise allowed us to talk about issues of intimacy did we discover the emic view: the mask used by the participant to help him sleep blew air out the side, so bothering his spouse that she had constructed the ridge of blankets to separate herself. They had to use that solution or sleep in different rooms.

One goal of a design research project is the construction of a well-informed etic view - a framing of our understanding in terms of the project's needs (which are of course outside the world of the people we are studying). To do so, we attempt to discover the emic understanding of objects - the meaning assigned to objects by the people who live with them. This helps us avoid the error of starting with our preconceived categories, our preconceived etic notions, projecting them onto the data while remaining tragically heedless of the emics. We have to start with the emic view ("I use blankets to protect myself from my husband's mask") to get to an etic view we can trust ("mask exhaust compromises intimacy").

Akama et al. describe indigenous artefacts as having knowledge embedded in them. In their case, it was a project team's process knowledge. The term embedded knowledge is a metaphor, of course. It is a useful metaphor, because it suggests questions about how the knowledge got in there, and how one might get it out. But like any metaphor it is imprecise.We might rather say the knowledge has been assigned to the artefacts by the people that use them, and it is worth checking to find out whether everyone involved has actually assigned the same meaning. The difference is small, but we find the notion of assigned meaning helps us when we are designing activities either to discover those meanings or engage people in assigning new meanings to artefacts. Furthermore, assigned meaning maps directly to another of Akama et al.'s points: the notion of the language of artefacts.

\section{Comment: Artefacts as language elements}

Akama et al. discuss the idea that artefacts can make up a "language", or even that there might be many languages of artefacts. This seems imprecise, if "language" is taken to mean a set of symbols with meanings shared between more than one person, and a set of rules for assembling those symbols to express new meanings. 
It seems more accurate to say that people create languages using artefacts as symbols, or more often extend written or spoken language by using artefacts as symbols. The pipe cleaner, the plastic bird, the sticky note - these become linguistic elements that are peer to any other entry in the lexicon.

I have sometimes witnessed a group create a small, standalone language of artefacts as they work with notes, diagrams and symbols on a wall over an extended period of time. Certain places on the wall come to have semantic significance; certain diagrams come to have rich meaning. Moving a sticky to a new place on the wall, or arranging several stickies in a new way, absolutely constitutes a speech act that is understood by everyone in the group. And the response may in turn be a new arrangement of notes and symbols on the wall. But, much more often, artefacts are used as linguistic elements in a sort of hybrid language made from both utterances and artefact manipulation.

[setting aside a card] “This doesn't interest
me."
[adding another pipe cleaner] “I talk to the
project manager every day.”
0: “Who else do you talk to?" A: [points to
three plastic ducks]

My colleagues and I believe many fields would benefit from a better understanding of how artefacts play a role in people's linguistic behaviour. A definition of language that restricts linguistic elements to spoken or written words offers little help to people designing communications, products, or services. I would advocate an understanding of language that treats visual elements, artefacts, gestures, and audible symbols as full-fledged linguistic elements. Most of us tend to restrict our idea of language to the set of symbols we can look up in a dictionary. A broader, and, I would argue, more hard-working view of language recognizes that the symbol set referenced in most communication is much larger than that.

Furthermore, researchers and designers would benefit greatly from an understanding of how people extend their language by agreeing together on new linguistic elements, or by learning and accepting those introduced from the outside (for example, in the form of the controls on electronic devices they acquire). I would argue that making a highway sign yellow is just as much an act of language use (in Highway Signish) as typing the word "warning" or making the sound /?uar'nın/ (in English). Sadly, we are missing a guiding theory to help us make use of that observation as we try to make choices about, for example, a television remote control that does not leave its users befuddled by the introduction of new linguistic elements into their lives (Rettig, 2006).

But, even without this theoretical understanding, knowing that artefacts do play a linguistic role leads to useful practical application. Akama et al.'s work and the gallery of examples in this paper hope to offer some evidence of the usefulness of recognizing the power of artefacts as meaningbearers.

\section{ACKNOWLEDGEMENTS}

Jenna Date was a key participant in the projects described in examples two, three, five and six, and played an equal role with the author in creating and conducting the methods. Lisa Bloss played a key role in examples three and six. Joanna Barth participated in the timeline collage work described in example one, and was the primary creator of the timeline construction kit.

\section{REFERENCES}

Akama, Y. Cooper, R. Vaughan, L. Viller, S. Simpson, M. \& Yuille, J. (2007). Show and tell: Accessing and communicating implicit knowledge through artefacts. Artifact, 1 (3), 172-181.

De Leon, J. \& Cohen, J. H. (2005). Object and walking probes in ethnographic interviewing. Field Methods, 17 (2), 200-204. Retrieved October 19, 2007, from http://fmx.sagepub. com/ cgi/reprint/17/2/200.pdf

Franklin, K. J. (1996). K. L. Pike on etic vs.emic: A review and interview. Retrieved October 5, 2007, from http://www.sil. org/klp/karlintv.htm

Pike, K. L. (1957). A stereoscopic window on the world (Language and life, part 1). Bibliotheca Sacra, 114, 141-156. Retrieved October 12, 2007, from http://personalwebs. oakland.edu/kitchens/150d/pike.html

Pike, K. L. (1993). Talk, thought, and thing: The emic road toward conscious knowledge. Dallas, TX: Summer Institute of Linguistics. 
Rettig, Marc (2006). Interaction design is language design.

Retrieved October 5, 2007, from Marc Rettig's Place on the World Wide Web: http://www.marcrettig.com/writings/

rettig_Interaction Languages.pdf

\section{CORRESPONDENCE}

Marc Rettig, Fit Associates, LLC,

5744 Ellsworth Avenue,

Suite 2A,

Pittsburgh, PA 15232, USA.

E-mail:marc@fitassociates.com

ISSN 1749-3463 print/ ISSN 1749-3471

DOI: $10.1080 / 17493460701819462$

(C) 2007 Danish Centre for Design Research 